\title{
Bariatric Psychology, Psychological Aspects of Weight Loss Surgery
}

\author{
Gerbrand van Hout ${ }^{\mathrm{a}}$ Guus van Heck \\ ${ }^{a}$ Department of Medical Psychology, Catharina Hospital, Eindhoven, \\ ${ }^{\mathrm{b}}$ Department of Medical Psychology and Neuropsychology, Tilburg University, the Netherlands
}

\section{Key Words}

Obesity · Psychological aspects · Surgery

\section{Summary}

Obesity is the 'disease of the 21st century' and results in physical and psychosocial co-morbidities as well as poor quality of life ( $\mathrm{OoL})$. In contrast to the nonsurgical treatment of obesity, bariatric surgery is treatment of choice for morbid obesity. Since improved QoL and enhanced psychosocial functioning are important goals of bariatric surgery, success following bariatric surgery should not only include weight loss and improvement or cure of co-morbid conditions, but also improvements in eating behavior, psychosocial variables, and QoL. Unfortunately, bariatric surgery does not lead to identical results in every patient. Patients who fail to adjust their eating behavior and lifestyle after bariatric surgery may experience adverse reactions. Compliance and adjustment may be attributed largely to psychological factors, implying that the operation on its own represents only one element in bariatric surgery. Considering the role of psychosocial factors in the outcomes of bariatric surgery and the impact of the operation on the psychological and social situation, mental health professionals should be a part of the process of evaluation and treatment of bariatric surgery patients. In the Netherlands, between 2000 and 2005, bariatric surgery has increased tremendously, and most Dutch hospitals have a multidisciplinary selection process.

\section{Introduction, the Burden of Obesity}

The prevalence of obesity has reached epidemic proportions; obesity is one of the largest public health concerns and is called the 'disease of the 21 st century' $[1,2]$. Obesity is an international disease that is spreading worldwide, in the Western world as well as in the Third World [3]. The epidemic is rampant in the USA; however, Europe is not far behind, especially in Southern and Eastern European countries [4]. In Europe, obesity affects $10-25 \%$ of the male population and 10 $30 \%$ of the female population [5]. In the Netherlands, about $12 \%$ of adults are obese, this number has doubled in the last decades [6]. As obesity increases, so does the advancement to the severe form, morbid obesity; in fact, one of the most rapidly growing segments of the obese population is that of the morbidly obese [7].

Obesity results in physical and psychosocial co-morbidities, as well as poor quality of life (QoL) [8]. It is associated with an increased risk of morbidity and premature mortality from numerous related medical conditions [9]. Because of these co-morbid conditions, obesity is responsible for more than 2.5 million deaths per year worldwide [10]. The loss of life expectancy due to obesity is marked, and can be up to 20 years shorter in severe obesity [11]. The most serious adverse health conditions are associated with morbid obesity; the more severe the obesity, the more serious the medical complications and mortality risk, hence the term 'morbid'.

In addition to an increased risk of physical morbidity and mortality, obesity is associated with debilitating psychological and social consequences as well as impaired QoL, especially in morbidly obese patients seeking surgical treatment $[12,13]$. Their QoL in general is worse compared to patients with other chronic diseases [14]. Obesity is nowadays associated with greater morbidity and poorer health-related QoL (HRQoL) than smoking, problem drinking, or poverty [15].

\begin{tabular}{ll}
\hline KARGER & $\oplus$ 2009 S. Karger GmbH, Freiburg \\
Fax +497614520714 & Accessible online at: \\
Information@Karger.de & www.karger.com/ofa \\
www.karger.com &
\end{tabular}

Dr. psy. Gerbrand van Hout

Department of Medical Psychology

Catharina Hospital

PO Box 1350, 5602 ZA Eindhoven, the Netherlands

Tel. +40 2396-200, Fax -239

gerbrand.v.hout@cze.nl 
Psychopathology may be conceived of as a co-morbidity of morbid obesity, mainly consisting of depression, anxiety, and impaired self-esteem [16]. The eating behavior of the morbidly obese is believed to be characterized by dieting and rigid control, alternating with disinhibition, compulsive eating, and attacks of binge eating, but also by noncompulsive overeating, such as frequent snacking (grazing) on high-calorie foods and beverages $[16,17]$.

Within the social domain, people with obesity have to deal with stigmatization, prejudice, discrimination, social isolation, unsatisfactory relations, and occupational problems $[18,19]$. Often their obesity is viewed as the reflection of a character flaw, and their psychosocial problems are attributed to their character rather than to their obese condition [20]. As a result, patients often feel misunderstood, neglected, and rejected, not only in social situations and at work but also by health care professionals [20]. Early in their morbid obesity, patients may not yet manifest the above mentioned physiological and psychosocial sequelae [21]. However, these patients, for instance, cannot cross their thighs, put on socks or boots, cut their toenails, or tie their shoelaces [22]. Finally, the obesity-related diseases are associated with a major and increasing medical care cost burden [23].

\section{Etiology of Obesity}

Obesity is believed to be the consequence of the complex interplay of genetic, social, cultural and environmental factors [20]. Our prehistoric ancestors were hunter-gatherers and were programmed for times of famine. Those who were best able to assimilate and store energy for periods of hunger survived by natural selection. They passed on so-called 'thrifty' genes, which may be partially responsible for the modern overweight and obesity epidemic [24]. However, because the increase in obesity in the last decades has been so rapid, it cannot be related purely to genetic change. Therefore, the current view is that the rapid increase in obesity is largely related to lifestyle-sedentary and high-calorie fast-food nutritional changes, linked to advancing technology of convenience and the ready availability of energy-dense foods [22]. Apart from a genetic predisposition to weight gain and an 'obesogenic' environment [25], behavior can account for a considerable proportion of weight variability. In other words, genetic factors determine predominantly whether individuals can get obese while lifestyle and the environment determine whether they actually do get obese [26]. This leaves a considerable proportion of weight variability open to behavioral modification [27].

\section{Treatment of Obesity}

There is little optimism about the long-term efficacy of nonsurgical treatment of obesity, such as diets, behavioral modi- fication, exercise, and pharmacotherapy [28]. Nonsurgical treatments are especially ineffective in reaching medically significant weight loss in the morbidly obese [28]. In contrast to more conservative treatments, bariatric surgery has provided means of treating morbid obesity successfully, bringing about sustained weight loss [29]. Although bariatric surgery does not treat the etiology of morbid obesity, it is an effective intervention which results in 40-60\% reduction of excess weight [30]. In addition to substantial weight reduction and improvement or cure of co-morbidities [31], bariatric surgery leads to a reduction of psychopathology and disturbed eating behavior as well as to a better QoL [32].

Bariatric surgery has been broadly accepted as the treatment of choice for morbid obesity [33]. As a result, in recent years, the demand for bariatric surgery has increased, and the number of procedures performed has increased dramatically. However, although more bariatric operations are performed each year, this serves only a small fraction of subjects qualifying for bariatric surgery [34].

\section{Bariatric Surgery}

Bariatric surgery falls into three categories: i) surgeries relying primarily on the mechanism of malabsorption, ii) operations relying primarily on gastric restriction, and iii) combined procedures. Because of its complications, purely malabsorptive procedures have been replaced by gastric restriction and combined operations. Gastric restrictive surgery such as vertical banded gastroplasty (VBG) and adjustable gastric banding (AGB) reduce stomach capacity and limit gastric outlet; as a result, food intake is restricted. Combined restrictivemalabsorptive procedures such as Roux-en-Y gastric bypass (RYGBP) combine a reduced stomach capacity with malabsorption.

Restrictive procedures are generally considered safe and quick to perform, and usually lead to satisfactory short-term weight loss results [35]. On the other hand, the success of these procedures in terms of long-term weight loss and quality of eating has been questioned [36]. Malabsorptive and combined procedures are associated with better long-term weight loss results and less dietary restriction, but do have a greater potential for serious perioperative and postoperative metabolic complications.

RYGBP is the most commonly performed bariatric surgery procedure worldwide, representing nearly $65 \%$ of all bariatric operations [29], and accounts for $80-90 \%$ of bariatric surgeries performed in the USA [37]. However, despite the great benefit provided by the weight loss, RYGBP could cause functional digestive symptoms; as a result, AGB is also gaining popularity in the USA [37]. While in the USA, RYGBP is the gold standard, in Europe AGB is the most performed technique [38]. 


\section{Outcome following Bariatric Surgery}

Improved QoL and enhanced psychosocial functioning are important goals of bariatric surgery and may motivate patients to adhere to health behaviors that maintain the surgically established weight loss $[22,25]$. Therefore, success following bariatric surgery should not only include weight loss and improvement or cure of co-morbid conditions but also improvements in eating behavior, psychosocial variables, and QoL [26].

After bariatric surgery, patients report that they have a sense of control of food intake that they never had before. Following bariatric surgery, patients are forced to reduce the amount of food intake and to change their diets [39]. They are instructed to eat only three small meals a day, to eat very slowly, to chew food extremely well, to eat small amounts, to stop eating when they are getting 'full', and to avoid high-calorie foods and liquids. However, preference for high-calorie soft food, such as ice-cream, is one of the main reasons for therapeutic failures. If a patient constantly snacks on high-calorie liquid or soft foods, it is possible to consume excess calories and frustrate the inhibition of the procedure. Such behavior results in minimal weight loss or actual weight gain. Bariatric surgery requires lifelong compliance with behavior changes by the patient to maintain the weight loss [40].

Following bariatric surgery, improvements are found in personality features, psychopathology, depressive symptoms, body image, eating behavior, social functioning, and HRQoL; most improvements are seen in the first one or two years after surgery [41]. However, studies show great variation in outcome, and, unfortunately, bariatric surgery does not lead to identical results in every patient. After initial success in the first years after surgery, weight may stabilize or may even increase. Some patients regain their weight, sometimes after developing an eating disorder. Also, psychological improvement and improvements in eating behavior and QoL may diminish. Some patients express a need for psychiatric or psychological treatment [20] which can be figured out by adequate postoperative psychological assessment, preferably by using both an interview and questionnaires.

Nevertheless, most patients are quite satisfied with their weight loss and other long-term results of bariatric surgery. In line with this, they report that they would opt for the operation once more, even despite relatively limited weight loss, limitations in postoperative eating behavior, and adverse side effects [9]. Apparently, patients achieve most of their goals even though not all of them obtain their desired weight loss [42]. In contrast, other studies have reported that some patients remain dissatisfied despite excellent weight loss [43]. For these patients, the benefit of the operation may not have warranted the risk. Up to $20 \%$ of patients appears to be dissatisfied, partly due to psychosocial problems, surgical complications, and the fact that the surgery did not meet their expectations [9].
Although the success of bariatric surgery is not $100 \%$, the results have to be seen in the light of the serious risks for somatic and mental health of untreated morbid obesity. Moreover, the surgical treatment of morbid obesity may be more costeffective over the long term than nonsurgical methods or no treatment at all, due to improvements in co-morbidities [44].

\section{Multidisciplinarity}

Some patients request surgery as a 'mechanical' solution to their disease, in order to feel less hungry and to need less willpower to stop eating [45]. Although most patients realize that surgery is just a tool and that they will have to take on a great deal of responsibility themselves in changing their eating and exercise habits [46], some studies report high percentages of noncompliance to postsurgical treatment regimes [47]. As time goes by, patients may be able to eat more and may start experimenting. Some patients report a feeling of loss of control over eating as early as 6 months postoperatively, when 'grazing' (frequently eating relative small amounts of, mostly highcalorie, food) can become a common behavior. Some patients may return to preoperative disturbed eating patterns such as emotional eating (eating in response to negative emotional states) and/or binge eating (eating a great amount of food in a short period of time, mostly superimposed on mood disorders or personality disorders). Others may develop eating disorders such as grazing only postoperatively [46].

Patients who fail to adjust their eating behavior and lifestyle after bariatric surgery may experience adverse reactions, e.g. premature cessation of weight loss and regain of weight, eating disorders, psychopathological symptoms, and deterioration in QoL [12].

However, it is not fully understood why there are differences in the outcomes of bariatric surgery. In addition to medicalsomatic and surgical-technical factors, successful outcomes largely depend on patients' abilities to implement permanent lifestyle changes such as adjustment of eating patterns, adhering to a strict nutritional and exercise regimen, and acquiring adequate coping skills to decrease emotional eating [48]. Compliance and adjustment may be attributed largely to psychological factors, implying that the operation on its own represents only one element in bariatric surgery [27, 47]. In fact, bariatric surgery implies a forced behavior modification.

Most experts agree that nonsurgical factors such as personality, psychosocial, and behavioral factors contribute to successful postoperative outcomes and that patients' psychological factors may be predictive of postsurgical adjustment [28]. Therefore, in most guidelines, assessment of bariatric surgery candidates by a multidisciplinary bariatric team, including a mental health professional, is recommended $[49,50]$. A multidisciplinary team, consisting of a group of professionals from a wide range of health-related disciplines, including clinical medicine, nursing, psychology, exercise physiology, and dietetic sciences 
Table 1. Most frequently discussed topics in preoperative psychological interview

\begin{tabular}{ll}
\hline Topic & $\begin{array}{l}\text { Percentage of respondents } \\
\text { discussing this topic }\end{array}$ \\
\hline $\begin{array}{l}\text { Weight history, eating behavior, functions of eating, psychosocial } \\
\text { and psychiatric problems, expectations of bariatric surgery, } \\
\text { influence of overweight on mood and psychological functioning, } \\
\text { motivation for weight reduction and undergoing bariatric } \\
\text { surgery, attitude of the social environment on overweight, } \\
\text { dieting history }\end{array}$ & $95-100$ \\
\hline $\begin{array}{l}\text { Influence of overweight on social contacts and physical health, } \\
\text { attitude of social environment on bariatric surgery }\end{array}$ & $85-90$ \\
\hline $\begin{array}{l}\text { Influence of overweight on personality, relationship-building, } \\
\text { and present and past (sexual) relationships }\end{array}$ & $60-70$ \\
\hline
\end{tabular}

with expertise in morbid obesity, is responsible for the development, implementation, and evaluation of a comprehensive treatment program [49].

\section{Bariatric Psychology}

Considering the important role of psychosocial factors in the outcomes of bariatric surgery, the impact of psychosocial variables on QoL after surgery, and the fact that the operation can profoundly modify the psychological and social situation [27], mental health professionals should be a part of the process of evaluation and treatment of bariatric surgery patients [51]. The interest in the examination of potential psychosocial predictors of success after bariatric surgery lies in the identification of variables that predict the ability or the inadequacy of patients to adjust to the new life conditions determined by surgery. Revealing reliable and valid psychosocial and behavioral predictors of improvements in weight and health after bariatric surgery allows practitioners to effectively target patients at risk of a poor response, enables better patient selection, could guide surgeons in selecting the most appropriate type of operation for a particular candidate, and allows dietitians and mental health professionals to provide alternative therapies or preoperative and/or postoperative counseling to improve long-term outcomes $[12,13]$. However, there have been few systematic studies on the influence of psychosocial factors upon bariatric surgery outcomes, and no consistent and reproducible predictors have been found [3]. This suggests that postsurgical weight loss may be achieved independently of preoperative psychosocial factors. Therefore, there is no firm ground for the assignment of patients to different types of treatment, and, until now, there are no absolute psychosocial criteria for exclusion of candidates from obesity surgery $[14,28]$.

Although, in general, no psychosocial predictors of weight loss are found, it appears that changes in psychosocial functioning, eating behavior, and HRQoL can be predicted by preoperative psychosocial characteristics [52]. Therefore, it would be important to identify those aspects of a patient's psychological make-up, personality, and eating behaviors that are relevant to his/her adjustment after surgery.

\section{Bariatric Surgery and Psychology in the Netherlands}

In the Netherlands, in 2000, bariatric surgery appeared to be rather uncommon. There were long waiting lists, occasionally 2-3 years. Consequently, patients often went to private hospitals or health care institutions abroad. Although most Dutch hospitals had a multidisciplinary selection process before performing bariatric surgery, involvement of the psychological or psychiatric discipline was not optimal. Postoperative assessment and preoperative and postoperative treatment were infrequently performed, in spite of increasing knowledge that postoperative assessment is essential to provide adequate aftercare in case of unwanted consequences such as eating disorders, excessive alcohol consumption, relationship problems, and depression. In addition, preoperative and postoperative treatment are expected to enhance the success of bariatric surgery by treating psychopathology and/or helping patients to adjust to their dietary requirements.

Between 2000 and 2005, bariatric surgery has increased tremendously: performance of bariatric surgery had increased from almost 600 to more than 2,000 operations, mostly AGB. However, this growth in capacity seems to come short for the Dutch morbidly obese population. Most patients undergo restrictive procedures although certain patients, such as superobese patients with eating disorders and patients with high consumption of sweets, are reported to have better results with procedures which include malabsorption [53]. Also, despite the growth in bariatic surgery, in most Dutch hospitals relatively few operations are performed. Because the risk of postoperative complications appears to be greatest when hospitals host fewer than 50 operations per year [54], this may be an unwanted situation. In 2005, too, most Dutch hospitals had a multidisciplinary selection process, and mostly a mental health specialist was involved. However, although mental health professionals were involved in patient evaluation, there still was no consensus concerning psychological assessment [34]. Table 1 
displays the most frequently discussed topics by Dutch mental health specialists in preoperative psychological interviewing.

The Dutch bariatric practice considerably differs from that in neighbor country Flanders, the northern Dutch-speaking part of Belgium. In Flanders, more than three times as many bariatric operations are being performed; also substantial more RYGBPs are being performed. As a result, the waiting lists in Flanders are much shorter than in the Netherlands (1 versus 8 months). The popularity of AGB over RYGBP in the Netherlands does not reflect the worldwide situation which is mostly just the opposite [29]. However, primacy of restrictive procedures, especially AGB, is reported in most European countries [38].

The participation of mental health specialists in Dutch multidisciplinary bariatric teams is about the same as in the USA [48]; in this perspective, the Flemish bariatric practice appears to stay behind.

\section{Discussion}

Although there are mixed results regarding postoperative psychosocial functioning, eating behavior, HRQoL, and other outcomes after bariatric surgery, the overall improvements provide extra justification for the surgical treatment of morbid obesity. The outcomes following bariatric surgery are, to a large extent, mediated by factors reflecting psychosocial adjustment and compliance to adequate eating behaviors. Therefore, frequent short-term and long-term psychological evaluation as well as psychological support are recommended. The identification and treatment of postoperative problems such as disturbed eating can be critical to promote a successful outcome after bariatric surgery. Bariatric surgery alone is, without any doubt, not sufficient to sustain success; consequently, additional behavioral treatment is necessary.

The practice of bariatric surgery and bariatric psychology in the Netherlands asks for more variety in surgical procedures, a concentration of bariatric surgery in specialized hospitals, uniform guidelines for psychosocial screening and selection of bariatric surgery candidates, and a more extensive involvement of psychologists specialized in bariatric surgery. These psychologists should broaden their role beyond conducting traditional evaluations for patient screening, to include accurate presurgical education, interventions geared toward preparing patients for surgery, monitoring their postoperative results, and offering adequate aftercare. Thus, the evaluation would not be aimed solely at identifying predictors of success but would also include the development of individually tailored interventions to increase compliance and, consequently, contribute to the patients' postoperative success.

\section{Disclosure}

The authors declared no conflict of interest.

\section{References}

1 World Health Organization: Obesity: Preventing and Managing the Global Epidemic. WHO Obesity Technical Report Series 2000, no. 894. Geneva, World Health Organization, 2000

2 Rössner S: Obesity: the disease of the twenty-first century. Int J Obes 2002;26(suppl 4):S2-4.

$\checkmark 3$ Wolf AM, Falcone AR, Kortner B, Kuhlmann HW: BAROS: An effective system to evaluate the results of patients after bariatric surgery. Obes Surg 2000; 10:445-450.

14 James PT: Obesity: the worldwide epidemic. Clin Dermatol 2004;22:276-280.

$\checkmark 5$ James WP: The epidemiology of obesity: the size of the problem. J Intern Med 2008;263:336-352.

6 Seidell JC, Visscher TLS: Voeding en gezondheidobesitas [Food and health-obesity]. Ned Tijdschr Geneeskd 2003;147:281-286.

7 Deitel M. It's a fat, fat, fat, fat world! Obes Surg 2004; 14:869-870.

8 Van Hout GC, Leibbrandt AJ, Jakimowicz JJ, Smulders JF, Schoon EJ, Van Spreeuwel JP, Van Heck GL: Bariatric surgery and bariatric psychology: general overview and the Dutch approach. Obes Surg 2003;13:926-931.

- 9 Shai I, Henkin Y, Weitzman S, Levi L: Determinants of long-term satisfaction after vertical banded gastroplasty. Obes Surg 2003;13:269-274.

10 World Health Organization: World Health Report

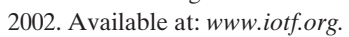

-11 Fontaine KR, Redden DT, Wang C, Westfall AO, Allison DB: Years of life lost due to obesity. JAMA 2003;289:187-193.
12 Dziurowicz-Kozlowska AH, Wierzbicki Z, Lisik W, Wasiak D, Kosieradzki M: The objective of psychological evaluation in the process of qualifying candidates for bariatric surgery. Obes Surg 2006; 16:196-202.

13 Wadden TA, Sarwer DB: Behavioral assessment of candidates for bariatric surgery: a patient-oriented approach. Obesity 2006;14:53S-62S.

14 Van Gemert WG, Severeijns RM, Greve JWM, Groenman N, Soeters PB: Psychological functioning of morbidly obese patients after surgical treatment. Int J Obes 1998;22:393-398.

15 Sturm R, Wells KB: Does obesity contribute as much to morbidity as poverty or smoking? Public Health 2001;115:229-235.

16 Van Hout GCM, Van Oudheusden I, Van Heck GL: Psychological profile of the morbidly obese. Obes Surg 2004;14:579-588.

17 Van Hout GCM, Van Oudheusden I, Krasuska AT, Van Heck GL: Psychological profile of candidates for vertical banded gastroplasty. Obes Surg 2006; 16:67-74.

18 Friedman MA, Brownel KD: Psychological consequences of obesity; in Fairburn CG, Brownell KD (eds): Eating Disorders and Obesity: A Comprehensive Handbook, 2nd ed. New York, Guilford Press, 2002, pp 393-398.

19 Dymek MP, le Grange D, Neven K, Alverdy J: Quality of life and psychosocial adjustment in patients after Roux-en-Y gastric bypass: a brief report. Obes Surg 2001;11:32-39.
20 Vallis TM, Butler GS, Perey B, Veldhuyzen van Zanten SJ, MacDonald AS, Konok G: The role of psychological functioning in morbid obesity and its treatment with gastroplasty. Obes Surg 2001;11: 716-725.

21 Deitel M: Overlooked problems in morbidly obese patients. Obes Surg 2001;11:541.

22 Deitel M: Bariatric surgery is a cost-saving for the healthcare system. Obes Surg 2005;15:301-303.

23 Thompson D, Wolf AM: The medical-care cost burden of obesity. Obes Rev 2001;2:189-197.

24 Deitel M: The obesity epidemic. Obes Surg 2006;16: 377-378.

25 Mathus-Vliegen EMH: Overgewicht. I. Prevalentie en trends [Overweight. I. Prevalences and trends]. Ned Tijdschr Geneeskd 1998;142:1982-1989.

26 Van Gemert W: Surgical treatment of morbid obesity: technical, psychosocial and metabolic aspects. Academical Thesis, Maastricht University, 1999.

27 Lang T, Hauser R, Buddeberg C, Klaghofer R: Impact of gastric banding on eating behavior and weight. Obes Surg 2002;12:100-107.

28 Hsu LKG, Benotti PN, Dwyer J, Roberts SB, Saltzman E, Shikora S, Rolls BJ, Rand W: Nonsurgical factors that influence the outcome of bariatric surgery: a review. Psychosom Med 1998;60:338-346.

29 Buchwald H, Williams SE: Bariatric surgery worldwide 2003. Obes Surg 2004;14:1157-1164.

30 Mun EC, Blackburn GL, Matthews JB: Current status of medical and surgical therapy for obesity. Gastroenterology 2001;120:669-681. 
31 Dyer RG: Traditional treatment of obesity: does it work? Baillieres Clin Endocrinol Metab 1994;8: 661-688.

32 Green AEC, Dymek-Valentine M, Pytluk S, Le Grange D. Alverdy J: Psychosocial outcome of gastric bypass surgery for patients with and without binge eating. Obes Surg 2004;14:975-985.

33 Horgen KB, Brownell KD: Confronting the toxic environment: Environmental, public health actions in a world crisis; in Wadden TA, Stunkard AJ (eds): Handbook of Obesity Treatment. New York, Guilford Press, 2002, pp 95-106.

34 Van Hout GCM, Vreeswijk CMJM, Van Heck GL: Bariatric surgery and psychology: Evolution of the Dutch approach. Obes Surg 2008;18:321-325.

\35 O'Brien PE, Dixon JB: Laparoscopic adjustable gastric banding in the treatment of morbid obesity. Arch Surg 2003;138:376-382.

-36 Balsiger BM, Poggio JL, Mai J, Kelly KA, Sarr MG: Ten and more years after vertical banded gastroplasty as primary operation for morbid obesity. J Gastrointest Surg 2000;4:598-605.

37 Santry HP, Gillen DL, Lauderdale DS: Trends in bariatric surgical procedures. JAMA 2005;294 1909-1917.

- 38 Hell E, Miller KA, Moorehead MK, Norman S: Evaluation of health status and quality of life after bariatric surgery: comparison of standard Roux-en Y gastric bypass, vertical banded gastroplasty and laparoscopic adjustable silicone gastric banding. Obes Surg 2000;10:214-219.

39 MacLean L, Rhode B, Shizgal H: Nutrition after vertical banded gastroplasty. Ann Surg 1987;206: $555-563$.
40 Brolin R, Robertson L, Kenler H, Cody RP: Weight loss and dietary intake after vertical banded gastroplasty and Roux-en-Y gastric bypass. Ann Surg 1994;220:782-790.

41 Van Hout GCM, Fortuin FAM, Pelle AJM, Blokland-Koomen ME, Van Heck GL: Health-related quality of life following vertical banded gastroplasty. Surg Endosc 2008;DOI: 10.1007/s00464-0089860-9.

42 Foster GD, Wadden TA, Vogt RA, Brewer G: What is a reasonable weight loss? Patients' expectations and evaluations of obesity treatment outcomes. J Consult Clin Psychol 1997;65:79-85.

43 Ballantyne GH: Measuring outcomes following bariatric surgery: weight loss parameters, improvement in co-morbid conditions, change in quality of life and patient satisfaction. Obes Surg 2003;13: 954-964.

44 Sampalis JS, Liberman M, Auger S, Christou NV: The impact of weight reduction surgery on healthcare costs in morbidly obese patients. Obes Surg 2004; 14:939-947.

45 Pessina A, Andreoli M, Vassallo C: Adaptability and compliance of the obese patient to restrictive gastric surgery in the short term. Obes Surg 2001;11: 459-463.

46 Glinski J, Wetzler S, Goodman E: The psychology of gastric bypass surgery. Obes Surg 2001;11: $581-588$.

47 Gentry K, Halverson JD, Heisler S: Psychologic assessment of morbidly obese patients undergoing gastric bypass: a comparison of preoperative and postoperative adjustment. Surgery 1984;95: 215-220.
8 Bauchowitz AU, Gonder-Frederick LA, Olbrisch ME, Azarbad L, Ryee MY, Woodson M, Miller A, Schirmer B: Psychosocial evaluation of bariatric surgery candidates: a survey of present practices. Psychosom Med 2005;67:825-832.

49 Gastrointestinal surgery for severe obesity 25-27 March 1991. Obes Surg 1991;1:257-265.

50 Tsigos C, Hainer V, Basdevant A, Finer N, Fried M, Mathus-Vliegen E, Micic D, Maislos M, Roman G, Schutz Y, Toplak H, Zahorska-Markiewicz B: Management of obesity in adults: European clinical practice guidelines. Obesity Facts 2008;1:106-116.

51 Herpertz S, Kielmann R, Wolf AM, Hebebrand J, Senf W: Do psychosocial variables predict weight loss or mental health after obesity surgery? A systematic review. Obes Res 2004;12:1554-1569.

52 Van Hout GCM, Hagedoren CAJM, Verschure SKM, Van Heck GL: Psychosocial predictors of success following vertical banded gastroplasty. Obes Surg 2008;DOI: 10.1007/s11695-008-9446-6.

53 Van Mastrigt GAPG, Van Dielen FMH, Severens JL, Vos GB, Greve JW: One-year cost-effectiveness of surgical treatment of morbid obesity: vertical banded gastroplasty versus lap-band ${ }^{\circledR}$. Obes Surg 2006;16:75-84.

54 Kuczmarski RJ, Flegal KM, Campbell SM, Johnson CL: Increasing prevalence of overweight among US adults: the National Health and Nutrition Examination Surveys, 1960 to 1991. JAMA 1994;272:205-211. 